\title{
In vitro repellency and contact bioassay of aqueous extracts of Cissus quadrangularis and Gomphocarpus physocarpus plants against Rhipicephalus evertsi evertsi ticks
}

\section{Mbusiseni V Mkwanazi}

University of KwaZulu-Natal School of Agricultural Earth and Environmental Sciences

Michael Chimonyo ( $\square$ michaelchimonyo@gmail.com )

University of KwaZulu-Natal School of Agricultural Earth and Environmental Sciences https://orcid.org/0000-0002-7767-2572

Sithembile Z Ndlela

University of KwaZulu-Natal School of Agricultural Earth and Environmental Sciences

Research article

Keywords: Acaricidal efficacy, bioactive compound, phytochemistry, tick mortality

Posted Date: December 6th, 2019

DOI: https://doi.org/10.21203/rs.2.18168/v1

License: (c) (1) This work is licensed under a Creative Commons Attribution 4.0 International License.

Read Full License 
$1 \quad$ In vitro repellency and contact bioassay of aqueous extracts of Cissus quadrangularis and Gomphocarpus physocarpus plants against Rhipicephalus evertsi evertsi ticks Mbusiseni V Mkwanazi, Sithembile Z Ndlela, Michael Chimonyo † Animal and Poultry Science, School of Agricultural, Earth and Environmental Sciences, University of KwaZulu-Natal, P Bag X01 Scottsville 3209, Pietermaritzburg, South Africa 


\section{Abstract}

30 Background: The frequent use of acaricides to control ticks and inadequate flock management

31 has led to the development of tick resistance to many acaricidal drugs. Ethno-veterinary plants

32 with acaricidal activities have a major potential to combat this challenge because they are easily

33 biodegradable, user-friendly, and less toxic to the environment and meat products. The objective

34 of the study was to assess the ethnoveterinary properties of Cissus quandrangularis. Lin and Gomphocarpus physocarpus E. Mey to control ticks.

36 Results: The $6 \%$ v/v of Cissus quadrangularis for each extract were more effective $(\mathrm{p}<0.01)$

37 against Rhipicephalus evertsi evertsi ticks. The repellency percentage was highest at $6 \% \mathrm{v} / \mathrm{v}$ for

38 acetone, methanol and control extracts similar to positive control Amitraz. The acaricidal efficacy

39 of the Gomphocarpus physocarpus at $12 \% \mathrm{v} / \mathrm{v}$ of methanol extracts was as good as that of $6 \%$

$40 \mathrm{v} / \mathrm{v}$, however different to that of $18 \% \mathrm{v} / \mathrm{v}$ was relatively low. The mortality rate of the control,

41 acetone was similar $(\mathrm{p}<0.05)$ between 6,12 and $18 \% \mathrm{v} / \mathrm{v}$ at $24 \mathrm{hrs}$. The mortality rate of the

42 positive control reached $100 \%$ after $72 \mathrm{hrs}(\mathrm{p}<0.05)$ post-treatment, even though it was similar

43 to that of acetone, methanol and control across different concentrations. The use of acetone and

44 methanol extracts resulted in similar tick mortality at 12 and $18 \% \mathrm{v} / \mathrm{v}$ at 24 hrs post-treatment.

45 The methanol extract of Gomphocarpus physocarpus at $6 \%$ v/v reached up to $100 \%$ mortality at $46 \quad 72$ hours similar to the positive control.

47 Conclusions: The bioassays indicated that there was a high efficacy percentage from the lowest concentrations (6\% v/v) of both Gomphocarpus physocarpus E. Mey and Cissus quadrangularis. Lin plant extracts, which was similar to the positive control (Amitraz) suggesting that suggesting that $6 \% \mathrm{v} / \mathrm{v}$ could be sufficient for recommendations because less plant material is required.

51 Keywords: Acaricidal efficacy, bioactive compound, phytochemistry, tick mortality 


\section{Background}

53 The abundance of ticks in the tropics and subtropics is a major challenge to goat productivity [1].

54 Ticks are prominent due to low veterinary services and lack of appropriate dipping systems for

55 goats [1]. The increasing temperatures and humidity in most parts of the Southern Africa coupled

56 with the abundance of wildlife that are main reservoirs of ticks create ideal conditions for tick

57 proliferation [2] and survival. Ticks cause anaemia, body condition loss, damage to skin and hides

58 [1]. Damages to teats and testes is also prevalent [3] and they transmit pathogenic viruses, rickettsia

59 and protozoal diseases endemic to most parts of Southern Africa, particularly ehrlichiosis [1]. The

60 frequent use of acaricides to control ticks and inadequate flock management has led to the

61 development of tick resistance to many acaricidal drugs.

63 The use of plant-derived remedies that have repellency and acaricidal activities can be a sustainable

64 alternative to address challenge of acaricide use. The application of plant-derived infusions,

65 concoctions and ointments to livestock has been reported to repel and kill certain mites, mange,

66 tsetse flies and ticks [4]. There is, however, paucity of information on the use of these

67 ethnoveterinary plants to control ticks in goats. Cissus quadrangularis is one of the plants where

68 almost all its parts are used in developing medicines. Gomphocarpus physocarpus (Apocynaceae)

69 is a small, upright and occasionally-branched shrub usually grows to 0.5 to $2 \mathrm{~m}$ tall. It occasionally

70 reaching up to $2.5 \mathrm{~m}$ in height. Despite the widespread and value of these plants for medicinal

71 purposes, little information is available about their acaricidal properties. Ethno-veterinary plants

72 with acaricidal activities have a major potential because they are easily biodegradable, user-

73 friendly, and less toxic to the environment and meat products. These plants produce primary and

74 secondary compounds that can be toxic [5] and repellent to ticks. 
76 Plant remedies are a potential source of undiscovered compounds with high biologically active 77 compounds against ticks and disease-transmitting vectors. Even though studies have been 78 conducted to determine the efficacy of plant species such as Aloe forex and Acokanthera 79 oppositifolia (Lam.) Codd [6;7] in controlling ticks, however, the acaricidal and repellency 80 properties of Cissus quadrangularis and Gomphocarpus physocarpus need to be determined. It

81 could be cheaper and easier to use than conventional acaricides $[4 ; 8]$. Farmers use them but

82 differently, it is important to standardise these so as to disseminate to other farmers without the 83 knowledge. There is need to investigate the effectiveness of plant species in controlling ticks in 84 goats $[9 ; 2]$. The objective of the study was to determine the in vitro repellency and contact 85 bioassay of aqueous extracts of Cissus quadrangularis Lin. and Gomphocarpus physocarpus E. 86 Mey plants against ticks. The study hypothesised that the use of plant aqueous extracts has no 87 acaricidal effects against tick infestation in goats.

\section{Methods}

89

\subsection{Study site}

91 The study was conducted in the Animal and Poultry Science laboratory, University of KwaZulu-

92 Natal. The study complied with the standards required by the Animal Research Ethics Committee 93 of the University of KwaZulu-Natal (Reference Number: AREC/043/017). 


\subsection{Description of plant material}

\section{Description of reference dip}

100 Eraditick 125 (Amitraz $12.5 \%$ w/v) is a registered commercial, non-systematic organophosphate

101 insecticide used by farmers to control external parasites in the study area. It was used as a reference

102 (positive control). It is effective against ticks, lice and mange.

\subsection{Plant collection and preparation}

105 Fresh leaves of Cissus quadrangularis and Gomphocarpus physocarpus used by farmers to control 106 tick infestation were collected in the bushes of Jozini area. Permission of plant collection was granted by the chief authorities and livestock association from Jozini Area. Following personal interviews with the chief authorities and livestock association, plant specimens were identified and collected. During collection of plant parts, leaves were collected as advised by farmers. The specimens were harvested, prepared, packaged and stored according to the herbarium rules and regulations. Plant specimens were authenticated at the Bews Herbarium, Department of Botany,

112 University of Kwa-Zulu-Natal. The voucher specimens were as follows: Cissus quadrangularis 113 Lin (NU0068142) and Gomphocarpus physocarpus E. Mey (NU0083347). Plants used were the 114 most used plants by farmers in the study site and based on a survey result from Mkwanazi et al.

115 [1]. The plant materials were thoroughly washed using distilled water and shaken to remove debris and tip off extra water droplets. Plant materials were macerated using an electric blender.

The prepared mixture was stored at room temperature overnight for $24 \mathrm{~h}$ before use and later strained using a muslin cloth. The concentration percentages of aqueous extract were determined to obtain a 6,12 and $18 \%(\mathrm{v} / \mathrm{v})$ extract. The treatments were calculated to provide a wide range 
121 of dosages that farmers normally use as described by Mkwanazi et al. [1]. Acetone and methanol

122 solvents were used to make these different concentrations. Water was used as a control. The

123 resulting extracts were stored in capped bottles in the refrigerator between 4 and $8{ }^{\circ} \mathrm{C}$ until use.

\subsection{Phytochemical screening}

126 Phytochemical screening of C. quadrangularis and G. physocarpus were carried out to assess the 127 qualitative chemical composition of crude extracts. The plants were tested for the presence of 128 tannins, alkaloids, saponin, flavoids and steroids. When testing for tannins $10 \mathrm{mg}$ of each plant 129 extract was dissolved in $45 \%$ of ethanol in test tubes. Test tubes were then boiled for 5 minutes 130 and $1 \mathrm{ml}$ of ferric chloride solution added to each. The appearance of greenish to black colour 131 indicated the presence of tannins in the extract. During the test of alkaloids the plant extract was 132 mixed in $1 \% \mathrm{v} / \mathrm{v}$, then warmed and filtered.

134 The filtrate was treated with Mayers reagent (Mercuric chloride + Potassium iodide in water). The 135 presence of alkaloids was shown by the formation of yellow coloured precipitates. During the test 136 of saponin about $10 \mathrm{mg}$ of each plant extract was diluted with $20 \mathrm{ml}$ of distilled water in test tubes.

137 Test tubes were hand-shaken for 15 minutes. Formation of a foam on the top part of a test tube 138 indicated the presence of saponin. When testing for the presence of flavoids $10 \mathrm{mg}$ of each plant 139 extract was added in test tubes, and few drops of $\mathrm{NaOH}$ was added on each tube. The appearance 140 of a yellowish colour showed the presence of flavonoids. In addition, when testing for steroids 141 about $10 \mathrm{mg}$ of each extract was added in test tubes, and $1 \mathrm{ml}$ of concentrated $\mathrm{H}_{2} \mathrm{SO}_{4}$ added by the 142 side wall of the test tube. The appearance of dark-reddish green colour indicated the presence of 143 steroids in the plant extract. 


\section{$144 \quad 2.5$ Statistical analyses}

145 For the analyses of tick repellency and mortality PROC UNIVARIATE (SAS, 2016) was used to 146 check data for normality. The collected data on repellency and contact bioassay were analysed 147 using PROC GLM procedure (SAS, 2016). In each case, ticks were used as an experimental unit. 148 Turkey test was used to compare differences between treatment means. Differences among the 149 least square means were considered significant at $\mathrm{p}<0.05$. The statistical model used was:

$150 \quad Y_{i j k l}=\mu+C_{k}+R_{j}+(C \times R)_{k j}+\varepsilon_{i j k l}$

151 Where; $\mathrm{Y}_{\mathrm{ijkl}}$ - is the response variable due to treatment (mortality and repellency);

$152 \mu-$ is the overall mean common to all observations;

$153 \quad \mathrm{C}_{\mathrm{k}^{-}}$is the effect due to concentration;

$154 \quad R_{j}$ - is the effect due to aqueous extracts;

$155(\mathrm{C} \times \mathrm{R})_{\mathrm{ikj}}-$ is the interaction between concentration and extract;

$156 \quad \varepsilon_{\mathrm{ijkl}}-$ is the residual error; 


\section{Results}

164

165

166

167

168

169

170

171

172

173

174

175

176

177

178

179

180

181

182

183

184

185

186

\subsection{Qualitative phytochemical screening}

Phytochemical screening of both C. quadrangularis and G. physocarpus are shown in Table 1. Screening of methanol, acetone and water extracts of Gomphocarpus physocarpus revealed the presence of saponin, alkaloids, steroids, flavoids and tannins. The presence of these phytochemicals differ with the extraction medium used. Alkaloids, phenolic, tannins and steroids were highly present when extracted with methanol, while saponin became highly present when using water extracts. Extraction using acetone revealed the presence of flavoids, steroids and phenolic and tannins (Table 1). Highly present reflect that the particular colour that is supposed to reveal the phytochemical present in a plant is strong. While moderately present means that the phytochemical are not that strongly present. Low means that the presence of phytochemicals is there but in low amounts as reflected by the presence of light colour. If the colour that is supposed to appear, however is not there it is reflected as absent.

The screening of Cissus quadrangularis on the other hand revealed the presence of saponin, alkaloids, steroids, flavoids and tannins. In the methanoic extracts, alkaloids were highly present, while in the acetone the presence of alkaloids were moderately present. The water extract had low alkaloids present. Phenolic and tannins were highly present in all extracts. Flavoids were highly present in the acetone and methanol extract, while in water it was moderately present. In the acetone and water extract the saponin were low while moderately present for methanol. Extraction using acetone and water revealed the presence of low steroids. In the methanol extracts steroids were moderately present. 
187

188

189

190

191

192

193

194

195

196

197

198

199

200

201

202

203

204

205

206

207

208

209

210

\subsection{In vitro repellency bioassay}

Tick repelling activity of $C$. quadrangularis.Lin at different concentrations are shown in Table 2. In vitro assay showed that both plants have positive acaricidal activity against ticks using different aqueous extracts. Repellency percentage of Cissus quadrangularis and different extraction solvents declined with time from $30 \mathrm{~min}$ to $5 \mathrm{hrs}$ (Table 2). The $6 \% \mathrm{v} / \mathrm{v}$ of Cissus quadrangularis for each extract were more effective $(\mathrm{p}<0.01)$ against Rhipicephalus evertsi evertsi ticks. The repellency percentage when extracting with acetone, methanol and control were similar at $12 \% \mathrm{v} / \mathrm{v}$. The repellency percentage of methanol reached up to $100 \%$ for Cissus quadrangularis at $6 \% \mathrm{v} / \mathrm{v}$. In the $18 \%$, v/v concentration the repellency percentage was very low compared to 6 and $12 \% \mathrm{v} / \mathrm{v}$.

When using Gomphocarpus physocarpus plant the efficacy decreased with time (p <0.01) from 30 min to 5 hrs, respectively (Table 3). The repellency percentage was highest at $6 \% \mathrm{v} / \mathrm{v}$ for acetone, methanol and control extracts similar to positive control Amitraz. The methanol extracts of Gomphocarpus physocarpus at $6 \%$ v/v produced repellency percentage similar to that of $12 \%$ v/v. The repellency percentage of positive control decreased with time from $30 \mathrm{~min}$ to $5 \mathrm{hrs}$. The acaricidal efficacy of the Gomphocarpus physocarpus at $12 \% \mathrm{v} / \mathrm{v}$ of methanol extracts was as good as that of $6 \% \mathrm{v} / \mathrm{v}$, however different to that of $18 \% \mathrm{v} / \mathrm{v}$ was relatively low. The methanoic extracts of Gomphocarpus physocarpus were so effective that it's reached up to $100 \%$ repellency at $6 \% \mathrm{v} / \mathrm{v}$ from $30 \mathrm{~min}$ to $1 \mathrm{hr}$. There was lower repellency activity from acetone and methanol at $18 \% \mathrm{v} / \mathrm{v}$. Acaricidal efficacy at $12 \% \mathrm{v} / \mathrm{v}$ for the control treatment was similar to that of $18 \% \mathrm{v} / \mathrm{v}$ ( $p>0.05)$, respectively. The efficacy of the control was the same $(\mathrm{p}<0.01)$ for Gomphocarpus physocarpus across all the concentrations from 3- 5 hours post-treatment. 


\section{$211 \quad 3.2$ Contact bio-assay}

212

213 Table 4 shows the in vitro mortality of Rhipicephalus evertsi evertsi ticks against Cissus 214 quadrangularis.Lin 72 hours post-treatment. The acaricidal efficacy of Cissus 215 quadrangularis increased with an increase in incubation period (Table 4). The mortality rate of the 216 control, acetone was similar $(\mathrm{p}<0.05)$ between 6,12 and $18 \% \mathrm{v} / \mathrm{v}$ at $24 \mathrm{hrs}$. The methanoic extracts 217 produced similar efficacy with the control at $4 \mathrm{hrs}$ post-treatment across the different 218 concentrations $(\mathrm{p}<0.05)$. The mortality rate of the positive control reached $100 \%$ after 72 hrs (p $219<0.05)$ post-treatment, even though it was similar to that of acetone, methanol and control across 220 different concentrations.

222 Table 5 shows the in vitro mortality rate of Gomphocarpus physocarpus against ticks. Tick 223 mortality at $6 \% \mathrm{v} / \mathrm{v}$ for acetone, methanol and control at $24 \mathrm{hrs}$ post-treatment were similar to that 224 of positive control ( $\mathrm{p}<0.05)$. The use of acetone and methanol extracts resulted in similar tick 225 mortality at 12 and $18 \% \mathrm{v} / \mathrm{v}$ at $24 \mathrm{hrs}$ post-treatment. There was a similar tick mortality rate across 226 the methanol, control and positive control at different concentrations $(\mathrm{p}<0.05)$. The methanol 227 extract of Gomphocarpus physocarpus at $6 \% \mathrm{v} / \mathrm{v}$ reached up to $100 \%$ mortality at 72 hours 228 similar to the positive control. 


\section{Discussion}

Farmers in resource-limited areas use plant extracts to control parasites, including ticks. The use of repellent acaricides for goats protection against ticks, constitute an important prophylactic component of tick management strategy. Same applies to the contact acaricides, which are chemical agents meant to kill ticks and are toxic through contact action. In vitro techniques are preferred over in vivo methods due to their low cost, simplicity and rapid turnover [10]. Ethno veterinary plants have bioactive substances such as flavonoids, terpenoids, and alkaloids and phenolic that possesses acaricidal properties against ticks than commercial chemicals [11]. The search for alternative methods to control parasites including ticks envisages the importance of determining the efficacy of these plant remedies as it gives the dense understanding of the quality of the plants. Plant remedies used in the current study were identified to be the most used acaricidal agents against ticks.

\section{The aqueous extracts of both Cissus quadrangularis. Lin and Gomphocarpus physocarpus E. Mey} plants were acaricidal against Rhipicephalus evertsi evertsi ticks, though the pattern was not anticipated. It was expected that the highest acaricidal efficacy percentage would be from the highest aqueous extracts, however, the lowest concentration $(6 \% \mathrm{v} / \mathrm{v})$ for both studied plant materials were most effective. Such findings are similar to Madzimure et al. [12] who reported the highest efficacy ratio from the lowest concentration of $(5 \% \mathrm{w} / \mathrm{v})$. A probable explanation for these findings could be that the extraction process with both methanol and acetone contribute to the efficacy of the plant because they produce a more potent extract, which is similar to the control. Similar repellency percentage at 6 and $12 \%$ v/v for Cissus quadrangularis. Lin could probably be influenced by the similar polarity of methanol and acetone [13]. The high presence of alkaloids, 
259 tannins and flavoids in the methanol extract of Cissus quadrangularis could have contributed to

260 repellency. Tannins have been reported to bind the glycoprotein of the tick cuticle and lead to 261 mortality [14]. Zenebe et al. [15] reported that the phytochemical screening of Cissus 262 quadrangularis.Lin using methanol extract showed the presence of flavonoids and phenols.

264 The observation that the methanol extract of Gomphocarpus E.May and Cissus quandrangularis. 265 Lin the repellency percentage could reach $100 \%$ at a shorter duration may be attributed to the 266 ability of methanol to attract and also compromise the movement of ticks [13] efficiently. This 267 findings are corroborated by Santhoshkumar et al. [16] who found that the aqueous extract of $C$. 268 quadrangularis (stem) had acaricidal activity against Rhipicephalus (B.) microplus. Also, the 269 finding that extracting using $12 \% \mathrm{v} / \mathrm{v}$ Cissus quadrangularis. Lin at 1 hour was as good as that of $2706 \% \mathrm{v} / \mathrm{v}$ using methanol extract could be influenced by the presence of compounds such as $\beta$ 271 sitosterol (1), (22E)-3- $\beta$-hydroxycycloart-22-en-24-one, uvaol, daucosterol, methyl-3,4272 dihydroxybenzoate, emodin, 4-hydroxyphenyl-O- $\beta$-D-glucopyranoside, aloin B and rutin isolated 273 from the methanol extract [17]. Luseba et al. [18] and Zenebe et al. [15] reported that the methanol 274 extracts of stems of Cissus quadrangularis.Lin has shown to have antimicrobial activity. The 275 moderate levels of alkaloids in the methanol extracts, which has the ability to affects the 276 permeability of the cell membranes of ticks and cause vacuolization and disintegration [14].

277

278 The finding that methanol extracts of Gomphocarpus physocarpus at $6 \% \mathrm{v} / \mathrm{v}$ produced repellency 279 percentage similar to that of $12 \% \mathrm{v} / \mathrm{v}$ could probably be influenced by the increase in polarity as 280 the concentration increases. The observation that methanol extract of Gomphocarpus 281 physocarpus was able to extract a wide range of phytochemicals such as alkaloids, phenolic 
282 compounds, flavoids and asteroids could have contribute to the high solubility of methanol. These

283 secondary metabolites are considered as the chemical components responsible for wide acaricidal

284 activities for several ethnoveterinary plants $[19 ; 14]$.

285

286

Delayed repellency activity observed from all extracts including positive control from 4-5 hours

287 post-treatment could mean that as the time of application increases the polarity of the extracts

288 decreases, which might indicate that a lower concentration and shortened duration $(6 \%$ v/v)

289 provides the maximum activity for both Gomphocarpus physocarpus E. Mey and Cissus

290 quadrangularis .Lin plants and is adequate to control ticks. The similar efficacy of the positive

291 control amitraz and $6 \%$ Cissus quadrangularis. Lin and Gomphocarpus physocarpus E. Mey after

$29230 \mathrm{~min}, 1$ hour and 2 hours are difficult to explain. These findings, however corroborate that of

293 Benavides et al. [20] in which a $5 \%$ soapy aqueous seed extract of Azadirachta indica controlled

294 Boophilus microplus tick as effectively as an amitraz-based acaricide. The observed similar

295 repellency for the control treatment at 12 and $18 \% \mathrm{v} / \mathrm{v}$ for Gomphocarpus physocarpus from 3-5

296 hours post treatment could probably be due to the extraction medium used as different mediums

297 yield different results demonstrating the same strength as the positive control.

298

299 It is, however not precisely clear why the repellency efficacy at $18 \% \mathrm{v} / \mathrm{v}$ from acetone and methanol was lower for Gomphocarpus physocarpus. It is possible that at a higher concentration

301 of the extract the acaricidal properties of the plants were washed way such that they become less

302 effective against ticks. These findings are corroborated by Adamu et al. [21] who reported that at

303 higher dilutions the test extracts are moderately effective. The observed acaricidal efficacy of both

304 Gomphocarpus physocarpus E. Mey and Cissus quadrangularis. Lin aqueous extract at different 
305 concentrations increased with an increase in the incubation period for tick mortality rate are 306 contrary to Zenebe et al [15] who was of the view that mortality increases with an increase in the 307 relative concentration of the product.

309 The observed dose-dependent response across all extracts and concentrations for Cissus 310 quadrangularis is similar to Madzimure et al. [12] who reported a dose-dependent response to 311 acaricidal treatments from 24- 72 hours on tick mortality. The dose-dependent response of Cissus 312 quadrangularis. Lin shows that the duration of the treatments can influence the efficacy of the 313 material. The similar mortality rate at 6,12 and $18 \% \mathrm{v} / \mathrm{v}$ concentrations when extracted with water 314 and acetone at $24 \mathrm{hrs}$ could suggest that the main factors that influence the efficacy is the duration 315 of exposure to the test material and concentration. Sanhokwe et al. [7] reported that the 316 concentration of 30 and $50 \%$ Aloe forex acetone extracts was effective in causing Rhipicephalus 317 decoloratus and Amblyomma hebraeum tick mortality. Even though it was not expected for 318 acetone to produce such good findings due to its reported low efficiency of solvation [22]. Adults 319 ticks have a protective cuticle layer that is meant to protect the tick from dehydration and other 320 physical and chemical effects.

322 This cuticle is important in the reproduction process as a site of pheromone production [23].

323 Therefore, acetone and methanol extract being exceptionally good solvents to active components 324 of plants, they can dissolve the cuticle layer of ticks thus causing mortality. This could in part 325 explain the high mortality rate observed, which was similar to the positive control (100\%), when 326 extracted with acetone, methanol and control across different concentrations after 72 hours post 327 treatment. Even though it was expected that the control will yield positive results because it is 
328 regarded as a safe universal solvent for preparing traditional remedies. It is also worth noting that

329 several authors have raised concerns pertaining to the usage of water as a solvent because of high

330 polarity. The observation that at $6 \% \mathrm{v} / \mathrm{v}$ the mortality rate of Gomphocarpus physocarpus due to

331 acetone, methanol and control at 24 hours was similar to the positive control could be the

332 influenced by high active compounds extracted. Even though the high mortality rate at $6 \% \mathrm{v} / \mathrm{v}$ of

333 methanol extract is contrary to Sanhokwe et al. [7] who reported the highest mortality rate of 89

$334 \%$ using $50 \%$ methanol extract of A. oppositifolia.

335

336 The unexpected finding that acetone and methanoic extract of Gomphocarpus

337 physocarpus produced similar tick mortality rate at 12 and $18 \% \mathrm{v} / \mathrm{v}$ at $24 \mathrm{hrs}$ post treatment is

338 difficult to explain. A low larvae mortality after 24 hours in the methanol extracts [23]. A plausible

339 explanation for these finding could be due to the number of active compounds extracted that

340 depend on the solvent and method of extraction used. The similar mortality rate of Gomphocarpus

341 physocarpus at $6 \% \mathrm{v} / \mathrm{v}$ with positive control at 72 hours could be influenced by the presence of

342 hydroxyl $(-\mathrm{OH})$ on the methanol formula $(\mathrm{CH} 3 \mathrm{OH})$, which contains a greater negative charge than

343 the methane structure, thus making it every effective solvent. It is imperative to note that although

344 organic solvents are known for their superiority for extraction of bioactive ingredients, nonetheless

345 in the search of least cost animal health products for resource-limited farmers, the use of organic

346 solvents is limited by affordability. Henceforth, it could of interest to explore the use of different

347 alcohols that are most frequently used as liquor in rural retail outlets. 


\section{Conclusions}

352 The study revealed that the plant materials the farmers use as acaricides vary in terms of their

353 efficacy to control ticks. The efficacy of the different concentrations is influenced by the duration

354 of the application and the type of extracts used. Even though at higher concentration $(18 \% \mathrm{v} / \mathrm{v})$

355 the acaricidal plant treatments reduced low tick populations than expected, but the $6 \% \mathrm{v} / \mathrm{v}$

356 treatments for both repellency and mortality of ticks were as good as a commercial acaricide. Thus

357 the $6 \%$ concentration is sufficient for recommendations to farmers because less plant material is

358 required. While the current study corroborates that both Gomphocarpus physocarpus E. Mey and 359 Cissus quadrangularis. Lin are effective in controlling tick populations, however, it would be of 360 interest to further laboratory experiments to determine whether the plant extracts can reduce tick 361 feeding, moulting and fecundity.

\section{ABBREVIATIONS}

364 Not applicable

\section{ETHICS APPROVAL AND CONSENT TO PARTICIPATE}

367

The University of KwaZulu-Natal granted ethical clearance (Reference number: HSS/0852/017). The participants granted consent.

372 Not applicable. 
378 The datasets generated and/or analysed during the current study are not publicly available due to

379

380

\section{COMPETING INTEREST}

The authors declare that there is no conflict of interest.

\section{FUNDING}

The study was funded by the National Research Foundation (NRF) of the Republic of South Africa at the University of KwaZulu-Natal (Project name: Exploring indigenous knowledge systems, GUN: 112406). The funding covered all the aspect of logistics from data collection, analysis and the writing of the manuscript.

\section{AUTHORS CONTRIBUTIONS}

MVM, SZN and MC designed the study, MVM, SZN collected the data, MVM interpreted the data, and wrote the manuscript. All authors read and approved the final manuscript.

\section{ACKNOWLEDGEMENTS}

The authors appreciate the University of KwaZulu-Natal, Pietermaritzburg Campus for providing logistics needed for the study. We are grateful to the community of Jozini and livestock keepers for their contribution throughout the study. Co-operation of participants and the chairperson of Jozini Livestock Association M. Nkosi, is greatly acknowledged. The authors also acknowledge 
Mr Sithole (Jobe Mondise) and Mr Hlabisa (Nqina ka Ngono) from Makhathini Research Station

402 for assistance during plant collection.

AUTHORS INFORMATION

404

405

406

407

408

409

410

411

412

413

414

415

416

417

418

419

420

421

\section{References}

1. Mkwanazi, M.V, Ndlela, S.Z and Chimonyo, M. Utilisation of indigenous knowledge to control tick in goats: A case of KwaZulu-Natal Province, South Africa. Tropical Animal Health Production. 2019a.10.1007/s11250-019-02145-0.

2. Schwalbach, L.MJ, Greyling, J.P.C and David, M The efficacy of a $10 \%$ aqueous Neem (Azadirachta indica) seed extract for tick control in Small East African and Toggenburg female goat kids in Tanzania. South African Journal of Animal Science 2003; 33 (2): 8388.

3. Rocha, A., Starkey, P.H. \& Dionisio, A.C. Cattle production in Southern Mozambique. Agricultural Systems 1990; 37: 53-75.

4. Wanzala, W., Zessin, K. H., Kyule, N. M., Baumann, M. P. O., Mathia, E., \& Hassanali, A. Ethnoveterinary medicine: a critical review of its evolution, perception, understanding and the way forward. 2005.

5. Frenandez-Ruvalcaba, M., Cruz-Vazquez, C., Solano-Vergara, J. and Garcia-Vazquez, Z. Anti-tick effects of Stylosanthes humils and Stylosanthes hamate on plots experimentally 
infested with Boophilus microplus larvae in Morelos, Mexico. Experimental and Applied Acarology, 1999; 23: 171-175.

6. Moyo B. and Masika, P.J. Tick control methods used by resource-limited farmers and the effect of ticks on cattle in rural areas of the Eastern Cape Province, South Africa, Tropical Animal Health and Production 2009; 41: 517-523.

7. Sanhokwe, M., Mupangwa, J, Masika, P.J, Maphosa, V and Muchenje, V. Medicinal plants used to control internal and external parasites in goats. Onderstepoort Journal of Veterinary Research 2016; 1: 1-7.

8. Madzimure, J., Nyahangare, E. T., Hamudikuwanda, H., Hove, T., Stevenson, P. C., Belmain, S. R., \& Mvumi, B. M. Acaricidal efficacy against cattle ticks and acute oral toxicity of Lippia javanica (Burm F.) Spreng. Tropical animal health and production, $2011 ; 43(2), 481-489$.

9. Luseba D \& Van der Merwe D. Ethno veterinary medicine practices among Tsonga speaking people of South Africa. Onderstepoort Journal of Veterinary Research 2006; 73(2): 115-122.

10. Markus, S and M. Ernst. Medicinal Plants in Tropical Countries, Georg Thieme Verlag, Rudigerstrasse, Germany. 2005.

11. Edeoga, H. O., Okwu, D. E., \& Mbaebie, B. O. Phytochemical constituents of some Nigerian medicinal plants. African Journal of Biotechnology, 2005; 4(7), 685-688.

12. Madzimure, James, Emmanuel T. Nyahangare, Humphrey Hamudikuwanda, Thokozani Hove, Steve R. Belmain, Philip C. Stevenson, and Brighton M. Mvumi. "Efficacy of Strychnos spinosa (Lam.) and Solanum incanum L. aqueous fruit extracts against cattle ticks." Tropical animal health and production 2013; 1341-1347. 
13. Fouche, G., Sakong, B. M., Adenubi, O. T., Dzoyem, J. P., Naidoo, V., Leboho, T and Eloff, J. N. Investigation of the acaricidal activity of the acetone and ethanol extracts of 12 South African plants against the adult ticks of Rhipicephalus turanicus. The Onderstepoort Journal of Veterinary Research, 2017; 84(1).

14. Bauri, R. K., Tigga, M. N., \& Kullu, S. S. A review on use of medicinal plants to control parasites. Indian Journal of Natural Products and Resources (IJNPR)[Formerly Natural Product Radiance (NPR)], 2015;6(4), 268-277.

15. Zenebe, S., Feyera, T., \& Assefa, S. In vitro anthelmintic activity of crude extracts of aerial parts of Cissus quadrangularis L. and leaves of Schinus molle L. against Haemonchus contortus. BioMed research international. 2013.

16. Santhoshkumar, T., Rahuman, A. A., Bagavan, A., Marimuthu, S., Jayaseelan, C., Kirthi, A. V. and Velayutham, K. Evaluation of stem aqueous extract and synthesized silver nanoparticles using Cissus quadrangularis against Hippobosca maculata and Rhipicephalus (Boophilus) microplus. Experimental Parasitology, 2012; 132(2); 156-165.

17. Abdel-Shafy, S., \& Zayed, A. A. In vitro acaricidal effect of plant extract of neem seed oil (Azadirachta indica) on egg, immature, and adult stages of Hyalomma anatolicum excavatum (Ixodoidea: Ixodidae). Veterinary Parasitology, 2002; 106(1), 89-96.

18. Luseba, D., Elgorashi, E. E., Ntloedibe, D. T., \& Van Staden, J. Antibacterial, antiinflammatory and mutagenic effects of some medicinal plants used in South Africa for the treatment of wounds and retained placenta in livestock. South African Journal of Botany, 2008; 73(3), 378-383.

19. Debella, A. Manual for phytochemical screening of medicinal plants. Ethiopian Health and Nutrition Research Institute, Addis Ababa, Ethiopia, 2002; 35-47. 
20. Benavides, E., Hernández, G., Romero, N., Castro, A., \& Rodrígues, B. Preliminary evaluation of Neem (Azadirachta indica) extracts as an alternative for cattle tick, Boophilus microplus control. Rev Colomb Entomol, 2001; 27(1-2), 1-8.

21. Adamu, M., Naidoo, V., \& Eloff, J. N. Some southern African plant species used to treat helminth infections in ethnoveterinary medicine have excellent antifungal activities. $B M C$ Complementary and Alternative medicine, 2012; 12(1), 213.

22. Thouri, A., Chahdoura, H., El Arem, A., Hichri, A. O., Hassin, R. B., \& Achour, L. Effect of solvents extraction on phytochemical components and biological activities of Tunisian date seeds (var. Korkobbi and Arechti). BMC complementary and alternative medicine, 2017; 17(1), 248.

23. Nyahangare, E. T., Mvumi, B. M., \& Maramba, T. Acute oral mammalian toxicity and effect of solvents on efficacy of Maerua edulis (Gilg. \& Ben.) de Wolf against Rhipicephalus (Boophilus) decoloratus Koch, 1844 (Acarina: Ixodidae), Tick Larvae. BioMed research international. 2016. 